\title{
Resuene la Esfera (1734): una cantata de José Blasco de Nebra en el Monasterio de San Clemente de Sevilla
}

\section{Resuene la Esfera (1734): José Blasco de Nebra's cantata in the Monastery of San Clemente of Seville}

\author{
Alfonso Peña Blanco \\ Facultad de Teología San Isidoro de Sevilla \\ alfonsopebla@gmail.com \\ ORCID iD: https://orcid.org/0000-0003-3122-6988
}

\section{RESUMEN}

El monasterio de San Clemente de Sevilla atesora un rico patrimonio diplomático y documental que ha sido objeto de un pormenorizado estudio y catalogación. Sin embargo, hasta ahora, todo lo relacionado con la música conservada en el mismo no había corrido la misma suerte, siendo simplemente apilada sin ningún tipo de orden. No obstante, a través de este artículo queremos dar a conocer parte de un trabajo de acercamiento e investigación a este legado, así como una aproximación al género de la cantada o cantata y su funcionalidad dentro de la teatralidad de la liturgia contrarreformista. Igualmente, este hallazgo supone una contribución a la reconstrucción del contexto sonoro de la ciudad en esa época y a poder contemplar el monasterio como un verdadero espacio performativo en el Barroco.

Palabras clave: cantata, José Blasco de Nebra, siglo XVIII, San Clemente, Sevilla.

\section{Abstract}

The monastery of San Clemente of Seville treasures a rich diplomatic and documentary heritage that has been the subject of a detailed study and cataloging. However, until now, everything related to the music preserved in it had not known the same fate, being simply stacked without any kind of order. However, through this article we want to present part of an approach and research work on this legacy, as well as an approach to religious music gender and its functionality within the theatricality of the counter-reformist liturgy. Likewise, 


\section{Alfonso Peña Blanco}

this finding represents a contribution to the reconstruction of the sound context of the city at that time and to being able to contemplate the monastery as a true performative space in the Baroque.

Key Words: cantata, José Blasco de Nebra, $18^{\text {th }}$ century, Saint Clement, Seville.

Peña Blanco, A. (2021). Resuene la Esfera (1734): una cantata de José Blasco de Nebra en el Monasterio de San Clemente de Sevilla. Cuadernos de Investigación Musical, (13), pp. 5-15.

\section{INTRODUCCIÓN}

El Real Monasterio de San Clemente de Sevilla es, sin lugar a dudas, uno de los símbolos más significativo de la ciudad, siendo fundado por el rey Fernando III de Castilla en 1248 (Tabales, 1997, p. 70). Se trata de un centro religioso cuya erección fue instrumentalizada dentro de todo el aparato puesto en marcha tras la reconquista (Laredo, 1989, pp. 217-218). De hecho, el título de este monasterio, bajo la advocación de San Clemente, coincide con el día de la toma de Sevilla. Además, su estrecha relación con la Corona lo convirtió en fundación real, el más alto rango concedido a un centro de este tipo, algo ratificado al ser enterrada en él la reina María de Portugal, madre de Pedro I de Castilla. Posteriormente, durante los siglos XIV a XVI gozó de un momento de esplendor; ya que, junto a las aportaciones económicas de patronos y cofundadores, las religiosas que ingresaron durante esta época hicieron incrementar su patrimonio con sus dotes personales (Pérez, 2005, p. 147; Borrero, 1994, p. 502).

Por otra parte, el rico fondo documental del monasterio arranca desde el primer cuarto del siglo XIII (Borrero, 1996, p. 15). Con respecto al conjunto de obras musicales, las manuscritas del siglo XVIII conservadas en este centro son un total de 38, fechadas entre 1722 y $1744^{1}$. No obstante, por los datos recogidos en los libros de mayordomía podemos pensar que se trata de una pequeña muestra de la producción y actividad musical de este centro religioso durante esa época ${ }^{2}$. Del mismo modo, se constata una estrecha relación entre el monasterio y algunos de los músicos de los centros religiosos más importantes de la ciudad,

\footnotetext{
${ }_{1}$ Archivo del Real Monasterio de San Clemente de Sevilla (en adelante ARMSCS). Música manuscrita, siglo XVIII, legs. 1-6 (pendiente de catalogación).

2 Archivo del Real Monasterio de San Clemente de Sevilla (en adelante ARMSCS). Música manuscrita, siglo XVIII, legs. 1-6 (pendiente de catalogación).

${ }^{2}$ En la documentación del archivo del monasterio aparecen multitud de referencias sobre encargos y pagos por obras recibidas para distintas festividades del calendario litúrgico; cf.: ARMSCS. leg. $\mathrm{n}^{\circ}$ 55, libro de protocolo XXIII, fol. 387r; leg. $n^{\circ}$ 56, libro de protocolo XXVI, fol.378v; leg. $n^{\circ}$ 56, libro de protocolo XXIX, fol. 409r; leg. $n^{\circ} 58$, libro de protocolo XXIV, fol. 376v; leg. nº 59, libro de protocolo XXXVIII, fol. 369r; leg. 67. libro de protocolo LVII, fol. 621r; leg. 69, libro de protocolo XLII, fol. 465v; leg. 68, libro de protocolo LXIII, fol. 57r; leg. 69, libro de protocolo LXIV, fol. 401r.
} 


\section{RESUENE LA ESFERA (1734): UNA CANTATA DE JOSÉ BLASCO DE NEBRA EN EL}

Monasterio de SAN Clemente de SEVIlla

como la colegiata de El Salvador o la catedral, consistiendo en impartir clases a las novicias y la composición de algunas obras para distintas festividades.

De entre la nómina de autores del siglo XVIII que encontramos trabajando para el monasterio de San Clemente se encuentra la figura de José Blasco de Nebra. Este músico había ingresado en la catedral de Sevilla en 1736 como organista segundo (Isusi, 2003, p. 83). Sobre su origen, todo apunta a que provenía de una saga de organistas castellanos y que estaba emparentado con José de Nebra, vicemaestro de la capilla real de Madrid, aunque no está lo suficientemente demostrado (Martín, 1985, p. 186). Sobre su servicio para la sede hispalense conocemos que compaginó su ministerio en el órgano con la composición, conservándose en el archivo de la catedral un libro de misas que podrían ser de su autoría (Isusi, 2003, pp. 292-293). Además, en 1762 ganó la oposición a la cátedra de melodía en dicha sede, pasando también a la enseñanza y perfeccionamiento de algunos de los colegiales y de aquellos músicos que ingresaban en la capilla de música como principiantes (Isusi, 2012, pp. 145-146). Junto a este servicio, el organista segundo solía tener la responsabilidad de afinar y mantener el claviórgano y clave de la catedral. De este modo, estuvo trabajando para la catedral de Sevilla hasta 1780, falleciendo en la misma ciudad en 1785 (Isusi, 2012, p. 84).

En referencia al tema de nuestra investigación, la cantada de José Blasco de Nebra que damos a conocer nos permite acercarnos a la obra de un autor con una importante actividad musical en la Sevilla del siglo XVIII. Desde un análisis codicológico, se trata de una obra escrita en papel, con siete páginas en formato partichela de 21 x 30 centímetros en orientación horizontal. En su portada aparecen tanto el género de cantada como la autoría, lugar y fecha de composición, 1734, por lo que sitúa el trabajo en Sevilla de Blasco de Nebra dos años antes de ingresar como organista de su seo. Además, esta obra nos ayuda a esbozar parte del contexto sonoro de San Clemente y de la música en los monasterios femeninos sevillanos de esa época; ya que, aunque se han abordado distintos trabajos sobre la actividad musical en otras instituciones religiosas de gran importancia en la ciudad, aún hoy queda pendiente un estudio pormenorizado que arroje luz sobre la música en estos centros religiosos (Isusi, 2010; Gutiérrez, 2001).

\section{ANálisis de RESUENe la Esfera de José Blasco de Nebra}

La llamada cantada o cantata surge en España como influencia de la italiana entre el final del siglo XVII y principios del XVIII (Capdepón, 1999, p. 72). Sobre su origen, las fuentes nos permiten apuntar que surge en torno a la producción de los compositores que trabajaron para la corte de Felipe V (Torrente, 1997, pp. 114-115). A partir de 1713, se tiene constancia de la presencia de este género en Sevilla, por lo que en una década se había popularizado por todo el país, siendo un elemento presente en las iglesias al igual que en el resto de Europa. De esta manera, se introducen una serie de características propiamente italianizantes, como la estructura basada en la alternancia de recitativos y arias, que, en épocas muy tempranas, fueron mezclándose con otras de géneros propiamente españoles, esencialmente villancicos y tonadas, tales como los graves empleados a modo de conclusión. Al igual que las italianas, en España las que más predominan, sobre todo a partir de 1730, son las solistas con bajo continuo; aunque también aparecen en el acompañamiento otros 


\section{Alfonso Peña Blanco}

instrumentos (Capdepón, 1999, p. 72). Con respecto a la temática, dentro de este género podemos distinguir las cantatas religiosas de las profanas o cantadas humanas, cuyo tema predominante es el amor no correspondido y de las que se ha conservado un reducido porcentaje en comparación con las primeras (Carreras, 2000, pp. 127-141).

En el ámbito de la música religiosa, fue la cantata junto al villancico un elemento singular dentro del barroco español; ya que se trataron de obras en lengua vernácula que en ocasiones sustituyeron algún momento del oficio divino de una festividad litúrgica importante (Querol, 1983, pp. 118-119). De hecho, la obra Resuene la Esfera, es una cantata escrita, tal y como parece en el manuscrito, para tiple $1^{\circ}$, tiple $2^{\circ}$, alto, tenor $y$ acompañamiento de violín y bajo continuo, estando dedicada a la solemnidad de la Asunción de la Virgen María. El texto de la obra es el siguiente:

Introducción: Resuene la esfera de luces flamantes el eco sonoro, sonoro de voces suaves, suaves velozes amantes (que corren y brillan) al ver que las puertas del Cielo se abren.

Recitado: Ya los coros se escuchan de amantes seraphines, y en todos los confines con nuestros ecos luchan, queriendo en este día la elevación dichosa de María. Ángeles y hombres con igual victoria pretenden publicar cuya es la gloria.

Aria: Los coros celestiales publican la alegría llevándose a María a la feliz mansión. Saludan, su belleza por ser tan elevada que va a ser colocada con regia ostentación.

Aria à tres: Los coros celestiales publican la alegría llevándose a María a la feliz mansión.

Grave à tres: Pues goza de su vista sin rezelo, que suba de la tierra un cielo al Cielo.

Como podemos comprobar, la iconografía que se recrea en el mismo está basada en las fuentes literarias, apócrifas y canónicas, en torno a la Asunción de la Virgen María (Salvador, 2011, pp. 237-268). De esta manera, se encuentran presentes los elementos característicos que enmarcan la asociación del triunfo de la Virgen al de Jesucristo: su asunción al cielo rodeada de una corte celeste y su coronación por parte de la Trinidad. Del mismo modo, el ambiente festivo y de alabanza se asocia con su funcionalidad dentro de la liturgia contrarreformista. En la misma línea de los villancicos, estos números musicales, en lengua vernácula y con un carácter casi profano, se incluían dentro de la liturgia de las fiestas y solemnidades más importantes del calendario con el propósito de atraer el mayor número de fieles (García, 2003, pp. 67-69). Por este motivo, estas funciones musicales se apartaban de la liturgia oficial y fueron ampliamente criticadas por algunos sectores, aunque gozaron igualmente de una enorme popularidad. Por tanto, no es del todo extraño encontrar un ejemplo de este género asociado a una festividad mariana en el monasterio de San Clemente, teniendo en cuenta que era un centro religioso muy importante en la ciudad, con suficientes rentas para sufragar este tipo de gastos, asegurando así la concurrencia de fieles.

Por otra parte, en el género de la cantata encontramos una serie de adaptaciones que dieron lugar a una variedad de estilos y formas (Querol, 1983, p. 120). Sobre una base general en la que aparece la alternancia entre recitativos y arias para solistas, esta obra de Blasco de 


\section{RESUENE LA ESFERA (1734): UNA CANTATA DE JOSÉ BLASCO DE NEBRA EN EL}

Monasterio de SAN Clemente de SEvilla

Nebra se estructura mediante una sección inicial denominada introducción que antecede al recitado (traducción castellana del término italiano) del solista y que da paso a una aria à solo, a la que sigue otra aria y grave à tres voces. No obstante, las dos secciones que aparecen en el original denominadas como dos arias (y no área como traducción castellana usual en la época) deben considerarse como una única, siguiendo el esquema del aria da capo, cuya primera sección se repite en polifonía. El esquema de la obra seguiría por tanto este orden:

\begin{tabular}{cccc} 
INTRODUCCIÓN & RECITADO & ARIA & GRAVE \\
\hline cc. $1-16$ & cc. $17-26$ & cc. $27-129$ & cc. $130-138$ \\
\hline
\end{tabular}

Tabla 1: Esquema de la estructura de la obra.

La introducción es, por lo general, una sección breve que suele emplearse para establecer la tonalidad y la temática de la obra. De hecho, el diseño melódico de las distintas secciones responde a elementos presentados en la introducción, donde la parte instrumental realiza una especie de sujeto o tema. Así, tanto en las partes solistas como en las polifónicas, el discurso melódico se basa en elementos provenientes tanto de la cabeza, cuerpo y cola de este sujeto o tema y que se verán sometidos a distintos tipos de técnicas de desarrollo como la inversión, variación, progresión...

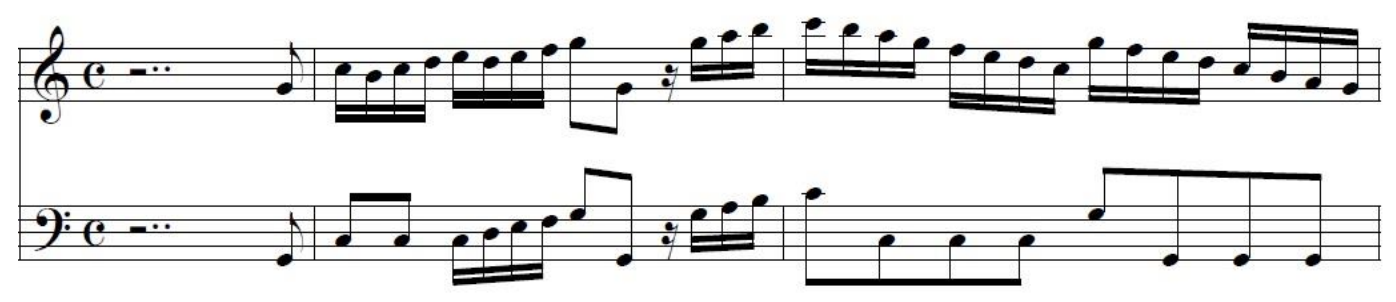

Fig. 1: Exposición del tema en el acompañamiento instrumental (cc. 1- 3).

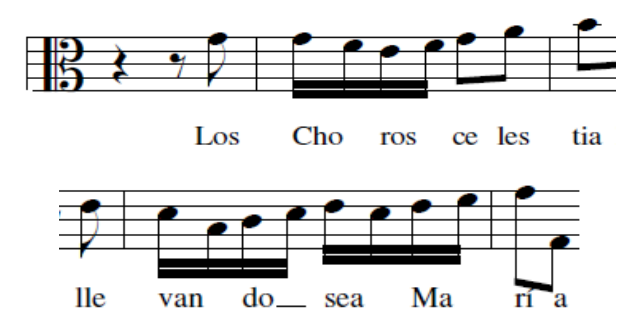

Figs. 2 y 3: Ejemplos de variación de la cabeza del sujeto. 


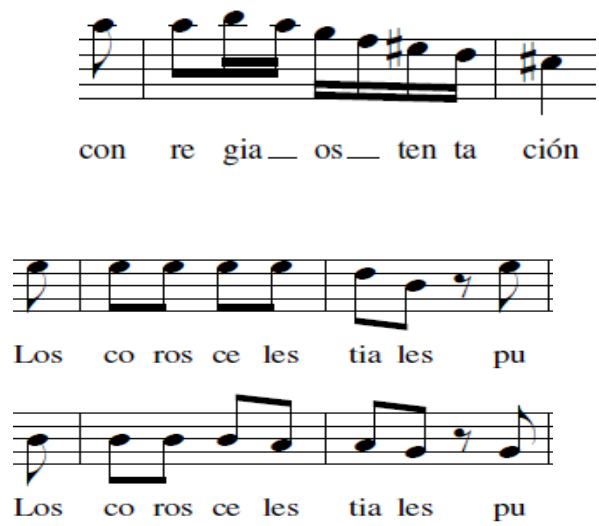

Figs. 4 y 5: Ejemplos de variación de la cola del sujeto.

En el manuscrito, esta sección y toda la obra aparece escrita en clave de Do en primera para el tiple $1^{\circ}$ y $2^{\circ}$, clave de Do en tercera para el alto y en cuarta para el tenor. Además, la indicación de tempo que aparece en la introducción es de a medio ayre. Asimismo, en esta cantata encontramos en su introducción dos textos, uno para el triple primero y alto y otro para el triple segundo y tenor, un recurso habitual en estas secciones, empleado para hacer avanzar la acción. De igual modo, se da cierto uso de la retórica, donde se recurre a distintos elementos melódicos y armónicos para enfatizar el significado del texto.

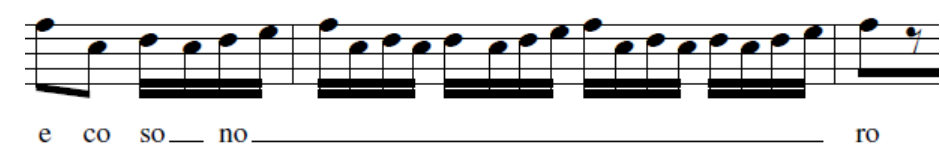

Fig. 6: Ejemplo del empleo de la retórica musical.

Como podemos comprobar en el ejemplo anterior, la repetición de un mismo diseño melódico se emplea para resaltar el sentido del texto, subrayándose la imagen de eco sonoro que se describe.

A la introducción le sigue la sección del recitado à solo o recitativo para la voz de alto. El hecho de que tanto esta sección como las dos primeras partes del aria estén escritas para esta tesitura, podría hacernos pensar que fueron escritas por José Blasco de Nebra pensando en una intérprete concreta. Lamentablemente, no tenemos datos que corroboren esta hipótesis y que nos pusieran en la pista de un miembro de la comunidad cisterciense de San Clemente o alguna alto de esta época relacionada con su labor compositiva.

Al margen de estas consideraciones, lo que sí constatamos es que esta sección está escrita en estilo de recitativo secco (Heller, 2017, p. 306), esto es, para solista y acompañamiento de bajo continuo. Con respecto al carácter, el sentido narrativo se enfatiza con el empleo de valores breves en la parte solista, mientras que el bajo se mueve en valores de blancas. Además, el uso del cromatismo hace de esta sección una región armónica inestable, que sirve para el enlace entre otras secciones de la obra. 


\section{RESUENE LA ESFERA (1734): UNA CANTATA DE JOSÉ BLASCO DE NEBRA EN EL}

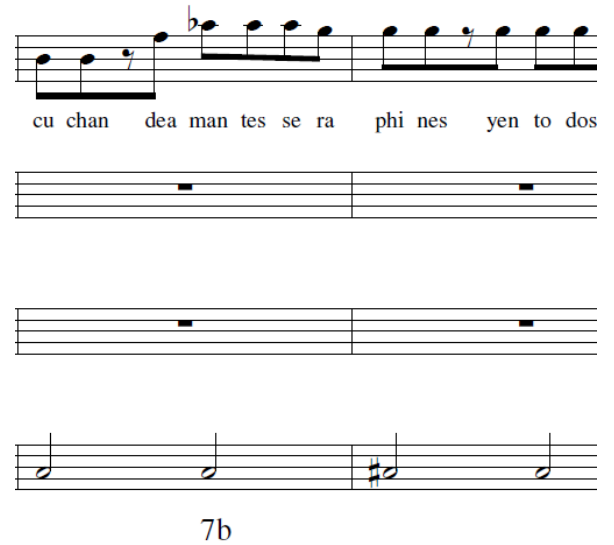

Fig. 7: Ejemplo del empleo del cromatismo.

En cuanto al aria que sigue al recitado, es la sección más extensa y reproduce el esquema del aria da capo (ABA') (Hill, 2008, p. 409). No obstante, como apuntábamos más arriba, la originalidad de esta aria es que las dos primeras partes están escritas à solo para alto, mientras que la repetición es interpretada por las tres voces restantes. Al margen de esta singularidad, el esquema que sigue es el propio de este tipo de arias. Así, con la indicación de tempo vivo, encontramos una primera parte que es más extensa que la segunda y que concluye en una cadencia perfecta $(\mathrm{D} / \mathrm{T})$ en la tonalidad principal. Por otra parte, la segunda sección es más breve, con un tiempo y carácter más dinámico que la primera y concluye en una cadencia en otro grado importante de la tonalidad (III), a modo de enfatización sin ninguna importancia estructural.

En estas dos partes del aria el acompañamiento de violín expone una frase melódica, como variación del tema presentado en la introducción de la cantata, que es retomada por el alto, sirviendo de base en todo momento para el desarrollo de ambas. Asimismo, estas dos partes presentan un único texto, que es sometido a la ornamentación y a ser fragmentado, por lo que el virtuosismo es el elemento que las caracteriza.

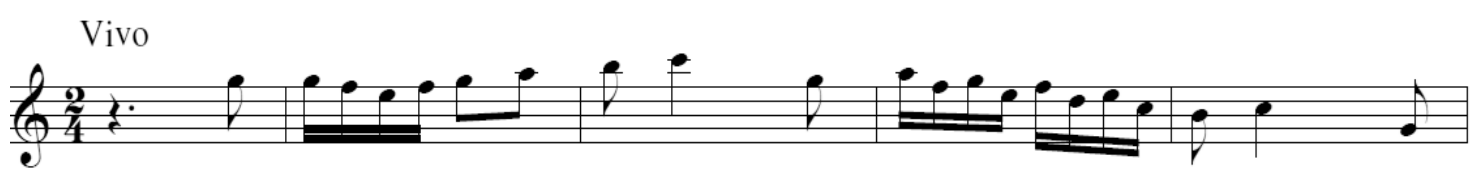

Fig. 8: Tema melódico expuesto por el violín del aria.

Todo esto contrasta con la repetición de la primera parte (A') en la que, aunque comienza por la misma frase melódica interpretada por el violín y la misma indicación de tempo vivo, predomina la homofonía y la articulación silábica, por lo que adquiere cierto carácter de estribillo. Sin embargo, dado que concluye en una cadencia perfecta en la tonalidad principal, no aparece ningún signo de repetición tras la segunda parte del aria y se retoma el mismo texto de la primera, estimamos incluir esta como una repetición estrófica 


\section{Alfonso PeÑa Blanco}

del aria más que como una parte independiente. Este planteamiento no debe extrañarnos dentro de la concomitancia que se dio entre elementos pertenecientes al género de la cantata y el villancico, sobre todo durante la primera mitad del siglo XVIII (Querol, 1983, p. 120). De hecho, dentro de la ingente producción de villancicos de esa época, encontramos ejemplos donde se alternan las partes solistas, que son auténticas arias sin la forma da capo, con estribillos polifónicos a cuatro, cinco o más voces.

Por último, la cantata concluye con la sección denominada grave, un elemento con reminiscencias del lamento teatral del siglo XVII y una de las secciones características de la cantata temprana del siglo XVIII (Carreras, 2000, p. 138; Torrente, p. 116). No obstante, se trata de una sección que guarda mucha semejanza en carácter y proporción con la del recitativo, predominando cierto tono narrativo; aunque con elementos propios, tales como el empleo enfático de intervalos disminuidos, las disonancias preparadas y un ritmo más lento. La función que desempeña esta parte a modo de final de la obra queda ratificada al moverse en todo momento en la tonalidad principal y en terminar en una cadencia conclusiva $(\mathrm{D} / \mathrm{T} / \mathrm{S} / \mathrm{T})$.

\section{CARACTERÍSTICAS MELÓDICAS Y ARMÓNICAS DE LA CANTATA RESUENE LA ESFERA}

Salvo en los momentos solistas, la melodía que encontramos en esta cantata es bastante silábica y de ámbito reducido, predominando el grado conjunto. La figura rítmica más empleada es la corchea, por lo que este elemento, unido a una textura eminentemente homofónica, hace que en las secciones de polifonía no se pierda cierto carácter de recitativo. No obstante, en las secciones solistas se aprecia cierto virtuosismo, con la introducción de saltos interválicos y figuraciones rítmicas más breves; aunque la melodía siga moviéndose predominantemente por grados conjuntos.

Con respecto a la textura, en la obra encontramos distintos tipos de tratamientos. La sección que corresponde a la introducción es quizás la parte más contrapuntística; en ella las cuatro voces van jugando con distintos elementos pertenecientes al referido sujeto expuesto por el acompañamiento instrumental. En cambio, las dos secciones siguientes, que corresponden al solo realizado por la voz de alto, se caracterizan por una textura de melodía sobre un simple acompañamiento armónico, realizado por el violín y el bajo continuo; aunque este adquiere un cierto protagonismo en los momentos en los que la voz queda en silencio. Las secciones que siguen, que corresponden al aria y grave à tres, presentan una textura homofónica y silábica.

Armónicamente, la obra permanece prácticamente todo el tiempo en la tonalidad de Do mayor, salvo algún momento puntual en el que encontramos alguna enfatización breve hacia la región de la dominante (cc. 48 - 54) y la tonalidad de La mayor (cc. 75 - 86). En la introducción, la tonalidad queda perfectamente presentada, ya que el autor incide en los grados de tónica y dominante durante todo el desarrollo de la misma. Asimismo, debido al carácter propio de la sección de recitativo, se mantiene el mismo planteamiento armónico haciéndose uso de acordes triadas. Igualmente, en el resto de secciones encontramos una armonía muy básica que pivota en todo momento sobre las funciones de tónica, subdominante y dominante, unido al uso de dominantes secundarias con la intención de 


\section{RESUENE LA ESFERA (1734): UNA CANTATA DE JOSÉ BLASCO DE NEBRA EN EL} Monasterio de SAN Clemente de SEVILla

enfatizar algún grado y siendo al mismo tiempo resultado de la utilización de apoyaturas, bordaduras o notas de paso. Del mismo modo, las cadencias que emplea y que van delimitando cada una de las secciones de la obra son muy claras y se articulan del mismo modo: $\mathrm{S} / \mathrm{D} / \mathrm{T}$; excepto la sección del aria à solo que termina en una cadencia abierta sobre el tercer grado de la tonalidad principal.

En referencia a la instrumentación, la obra está escrita para acompañamiento de violín y un continuo destinado a un instrumento de tecla. La parte de cuerda se caracteriza porque, salvo en ciertos momentos solistas, realiza un acompañamiento básico y reiterativo en base a melodías con muchas notas repetidas y grados conjuntos. Del mismo modo, el bajo continuo presenta un cifrado casi inexistente, encontrándose exclusivamente en aquellos lugares donde el autor quiere algún acorde de séptima.

Por último, con respecto al texto, no podemos precisar si la autoría del mismo se debió a José Blasco de Nebra, ya que no hemos hallado, hasta la fecha, ninguna referencia que nos lleve a esta afirmación. Sin embargo, resulta interesante encontrar un empleo del recurso de la retórica a lo largo de toda la obra, con elementos propios de la ópera. Esencialmente, el significado de texto se enfatiza a través de figuras retóricas melódicas, dándose sobre todo estructuras de repetición o líneas melódicas ascendentes, como apuntábamos en algunos de los ejemplos anteriores. Además, en cuanto a la temática, aunque la obra es religiosa, se intuyen algunos aspectos mitológicos propios de las cantatas profanas, lo que le confiere un importante grado de teatralidad y efectismo. Asimismo, este elemento convive con cierto matiz moralizante, al subrayarse que el carácter festivo que domina toda la obra obedece al triunfo glorioso del peregrinar terreno de la Virgen.

\section{CONCLUSiOnes}

Nos encontramos con un ejemplo representativo de las cantadas de la música española de ese periodo de la historia y en el que se dan préstamos de otros géneros propiamente hispanos, como es el caso del villancico. A pesar de poseer un planteamiento armónico y estructural básico, la obra denota un dinamismo y articulación que le otorgan un cierto grado de efectismo que acentúa su carácter de alabanza y festividad. Asimismo, el hecho de que el protagonismo de las partes de solo recaiga sobre la voz de alto le confiere un elemento de originalidad destacable y nos hace pensar en la posibilidad de que fuera escrita pensando en las características vocales de una intérprete concreta.

Por otra parte, representa una muestra de lo que supuso la actividad musical en el Real Monasterio de San Clemente de Sevilla en el siglo XVIII. Se trata de una evidencia de cómo la comunidad de religiosas de esa época contaba con algunos miembros doctos en música y en contacto con los máximos exponentes de la música sevillana. Por tanto, no se trataba de un centro religioso hermético, sino abierto a la ciudad y al intercambio cultural.

Al mismo tiempo, este ejemplo musical conservado en el archivo de San Clemente nos permite pensar en este monasterio como un espacio performativo, dentro de la línea de la liturgia contrarreformista propia del Barroco, donde la música jugaba un papel importante. De la misma manera, representa un original del contexto sonoro de la Sevilla de esa época 


\section{Alfonso PeÑa Blanco}

en otros centros religiosos menos estudiados, pero donde estaba presente la teatralidad y artificios de la liturgia barroca y el recurso de estos números musicales con la intención de atraer el mayor número de fieles. Se abre así una amalgama de conjeturas y de hipótesis de trabajo acerca del pulso interno y la vida ordinaria en este monasterio durante el siglo XVIII y, en este sentido, todo un campo de investigación hacia otros archivos monacales en espera de ser estudiados.

\section{BIBLIOGRAFÍA}

Borrero Fernández, M. (1996). Inventario General del Archivo de San Clemente de Sevilla, 2 vols. Sevilla: Fundación El Monte.

Borrero Fernández, M. (1994). Los monasterios femeninos en tiempos de Fernando III. Archivo Hispalense: Revista histórica, literaria y artística, LXXVII, pp. 495-508.

Borrero Fernández, M. (1991). El Monasterio de San Clemente el Real de Sevilla: un monasterio cisterciense en la Sevilla Medieval. Sevilla: Ayuntamiento de Sevilla.

Capdepón Verdú, P. (1999). Cantada. E. Casares (Dir.). Diccionario de la música española e hispanoamericana, vol. 3 (p. 72). Madrid: SGAE.

Carreras, J. J. (2000). Las cantatas españolas en la colección Mackworth de Cardiff. En M. Boyd \& J. J. Carreras (Eds.). La música en España en el siglo XVIII (pp. 127-141). Madrid: Cambridge University Press.

García Gallardo, C. L. (2003). Cantatas en Málaga: la música de Juan Francés de Iribarren (16981767). Jábega, VC, pp. 66-80.

Gutiérrez Cordero, M. R. (2001). La Música en la Colegiata de San Salvador. Granada: Consejería de Cultura. Centro de Documentación Musical de Andalucía.

Heller, W. (2017). La música en el Barroco. Madrid: Akal Música.

Hill, W. (2008). La música barroca. Madrid: Akal Música.

Isusi Fagoaga, R. (2012). Sevilla y la música de Pedro Rabassa: los sonidos de la Catedraly su contexto urbano en el siglo XVIII. Sevilla: Junta de Andalucía. Consejería de Cultura y Deporte.

Isusi Fagoaga, R. (2010). La música en la Catedral de Sevilla en el siglo XVIII y América: Proyección institucional, movilidad de los músicos y difusión del repertorio. En F. García-Abásolo González (Coord.). La música en las catedrales andaluzas y su proyección en 
RESUENE LA ESFERA (1734): UNA CANTATA DE JOSÉ BLASCO DE NEBRA EN EL

Monasterio de SAN Clemente de SEvilla

América. Córdoba: Universidad de Córdoba: Servicio de Publicaciones, Cajasur. Obra Social y Cultural.

Isusi Fagoaga, R. (2003). La música en la Catedral de Sevilla en el siglo XVIII: la obra de Pedro Rabassa y su difusión en España e Hispanoamérica. Granada: Universidad de Granada.

Laredo Quesada, M. A. (1989). Historia de Sevilla: La ciudad medieval (1248-1492). Sevilla: Servicio de Publicaciones de la Universidad de Sevilla.

Martín Moreno, A. (1985). Historia de la música española. Siglo XVIII, vol. 4. Madrid: Alianza Musical.

Pérez González, S. (2005). La mujer en la Sevilla de finales de la Edad Media: solteras, casadas y vírgenes consagradas. Sevilla: Secretariado de Publicaciones de la Universidad de Sevilla.

Querol Gavaldá, M. (1983). El cultivo de la cantada en España y la producción musical de Juan Francés de Iribarren (1698-1767). Musiker: cuadernos de música, I, pp. 115-128.

Salvador González, J. M. (2011) La iconografía de La Asunción de la Virgen María en la pintura del Quattrocento italiano a la lu乏. de sus fuentes patrísticas y teológicas. Mirabilia. Revista Electrônica de História Antiga e Medieval, XII, pp. 237-268.

Tabales Rodríguez, M. A. (1997). El Real Monasterio de San Clemente de Sevilla: una propuesta arqueológica. Sevilla: Universidad de Sevilla.

Torrente, A. (1997). La cantata española en los albores del setecientos. Scheræo, CXVII, pp. 114-117.

Fecha de recepción: 07/11/2020

Fecha de aceptación: 01/03/2021 